\title{
An Evaluation of an Engineering Leadership Development Program on Alumni Job Placement \& Career Progression
}

\section{Dr. Dena Lang, Pennsylvania State University, University Park}

Dr. Lang is the Associate Director of the Engineering Leadership Research Program at Penn State University. She holds a BS in Mechanical Engineering from West Virginia University, an MBA from Johns Hopkins University, and a PhD in Kinesiology with a focus on Biomechanics from Penn State University. Dr. Lang's previous professional experiences and research interests range from mechanical engineering facilities design to research that applied engineering and molecular biology approaches to the study of the skeletal response to mechanical loading. As a Mechanical Engineer, she worked on facility design projects involving mechanical systems that included heating, ventilation, air conditioning, and energy conservation systems, as well as R\&D of air conditioning equipment for Navy ships. Additional research interests have included the investigation of relationships among components of the indoor environment, occupants, and energy usage. Specifically, the effects of the indoor environment on occupant health and well-being and in parallel, how socially-mediated energy-saving strategies can increase awareness of energy use and/or increase energy saving behaviors. Dr. Lang's current research interests focus on identifying, assessing, and developing key skills, knowledge, attitudes, and other intrinsic and extrinsic factors required for engineers to effectively lead others, particularly other engineers and across cultures.

\section{Mr. Travis Gehr}

Dr. Meg Handley, Pennsylvania State University

Meg Handley is currently the Associate Director for Engineering Leadership Outreach at Penn State University. Previously, Meg served as the Director of the Career \& Corporate Connection's office at the Smeal College of Business at Penn State University. Meg completed her PhD in Workforce Education at Penn State, where she focused on interpersonal behaviors and their impact on engineering leadership potential.

Meg is a board certified coach with experience in developing students' leadership and professional competencies through teaching and one-on-one coaching. She is most interested in developing student knowledge of leadership to impact their successful transition to the workplace.

\section{Dr. John Jongho Park, Pennsylvania State University}

Dr. Park is an assistant research professor in the Engineering Leadership Program at Penn State University. There is four interrelated areas of inquiry characterize Dr. Park's scholarship: psychological attributes, professional identity development, group processes, and engineering leadership development. Particularly, he examines how possible future-self influences engineering students' learning, academic motivation, and career trajectory. The major population he primarily focuses on is STEM undergraduate and graduate students. He has received extensive qualitative and quantitative methodological training in the area of educational psychology. He acquired a Bachelor's of Science in Human Resources Management and a Masters of Educational Technology from California State University, Long Beach, and a Master's of Program Evaluation and a Doctorate of Philosophy from the University of Texas at Austin. Prior to joining the Penn State University, he worked as a research fellow and program evaluator at University of Michigan. Also he taught an "individual learning skills" as an assistant instructor in the University of Texas at Austin for five years.

\section{Mr. Andrew Michael Erdman, Pennsylvania State University}

Andrew M. "Mike" Erdman received his B.S. in Engineering Science from Penn State and his M.S. from USC. At Rocketdyne (Pratt \& Whitney), he helped design the Space Shuttle. As manager of Reactor Safety Analysis, Experimental Engineering, and Fluid Dynamics Technology at KAPL (Bechtel), he conducted research for Naval Reactors. He currently serves as the Walter L. Robb director of Engineering Leadership and as a Professor of Practice in SEDTAPP and Engineering Science at Penn State. Erdman has chaired the local Jaycees, Department of Social Services Advisory Council, GE Share Board, and 
Curling Club; and served on the Human Services Planning Council, United Way, Chamber of Commerce, and Capital Fund Drive Boards of Directors. Erdman has lectured on leadership topics at Penn State and RPI. He served as a recruiter (25 years) for GE and Lockheed Martin, on the Penn State College of Engineering Advisory Council, an Alumni Advisory Board, and as the President of the College of Engineering Alumni Society. Affiliations include Fellow of ASME, member of ASEE, AIAA, the Penn State Alumni Association, Centre County Chapter Board of Directors, President's Club, Nittany Lion Club. He has been honored with a LMC Leadership Award, GE Phillippe Award, PSEAS Outstanding service award, Jaycee International Senatorship, and an ESM Centennial Fellowship. 


\title{
An Evaluation of an Engineering Leadership Development Program Based on Alumni Job Placement \& Career Progression
}

\begin{abstract}
This is a 'work-in-progress' paper and is appropriate for the 'Inform' topic area. Leadership development programs have become an integral part of the engineering curriculum in order to meet the professional development needs of our graduates as well as the needs of their employers. This paper reports preliminary results from a survey of alumni from an undergraduate engineering leadership development program. The survey was developed to assess the degree to which the program is meeting its goals, which include ensuring that the program targets the skills needed in today's workplace, as well as enhance students' ability to land their first job and advance in their career. Graduates of the program $(n=136)$ were surveyed to better understand the impact of the program on their initial career placement, subsequent career advancement, and the development of skills needed for today's engineering work. Alumni were asked to rate their agreement (on a Likert-scale: Strongly Disagree, Disagree, Neutral, Agree, Strongly Agree) with the following statements: 1) The ELD program was instrumental in helping me get my first job. 2) The ELD program was instrumental in helping me get one or more promotions. and 3) The ELD program helped me develop skills needed for today's engineering work. These survey questions were intended to assess whether the alumni regarded their participation in the leadership development program as important in their initial hire and subsequent career progression. In addition, the third survey item was used to assess whether alumni believed that the program's developmental objectives were meeting the needs of our graduates in the workplace. Results from the alumni survey indicated that respondents felt that the ELD program was instrumental in helping ELD minor graduates in getting their first job (64\% responded strongly agree or agree) and in getting one or more promotions (57\% responded strongly agree or agree). In addition, the survey results indicate that respondents believed that the program helped to develop the skills needed for today's engineering work $(86 \%$ responded strongly agree or agree). Future work will explore whether participation in the leadership development program results in differences in salary level upon graduation compared to similar graduates not in the leadership program. In addition, follow up work will aim at better understanding where improvements can be made within the leadership development curriculum.
\end{abstract}

\section{Introduction and Background}

Many universities have incorporated leadership development programs into their curriculum, at both the undergraduate and graduate level. Through a review of the 2018 U.S. News and World Report, Reyes et al. (2019) reported that the top 50 ranked universities all offered some form of leadership development for their students.

With recent updates to the Accreditation Board for Engineering and Technology (ABET) criteria, criterion 3, student outcomes, now include several outcomes that are relevant to leadership develop programs: (2) an ability to apply engineering design to produce solutions that 
meet specified needs with consideration of public health, safety, and welfare, as well as global, cultural, social, environmental, and economic factors; (3) an ability to communicate effectively with a range of audiences; (4) an ability to recognize ethical and professional responsibilities in engineering situations and make informed judgments, which must consider the impact of engineering solutions in global, economic, environmental, and societal contexts; and (5) an ability to function effectively on a team whose members together provide leadership, create a collaborative and inclusive environment, establish goals, plan tasks, and meet objectives (ABET, 2020). While the inclusion of leadership development programs has been common practice for many disciplines, it has been on the increase within engineering programs, particularly over the last decade. A necessary component of any leadership development program is the ability to assess the effectiveness of the program and impact on students. Reyes et al. (2019) performed a meta-analysis of leadership development program evaluation in higher education. The aim of their analysis was to identify the design and delivery methods of leadership development programs that are best at developing students as leaders as well as identify gaps between management science and higher education practice, particularly when it comes to program evaluation.

Previous meta-analyses have mostly focused on the evaluation of leadership development programs as implemented within the workforce, examining the outcomes based on employee performance and participant feedback (Avolio et al., 2009; Burke \& Day, 1986; Collins \& Holton, 2004; Lacerenza et al., 2017; Powell \& Yalcin, 2010). Reyes et al. (2019) reported that their meta-analysis was the first attempt to examine leadership development effectiveness from the student perspective within a university context.

Reyes et al. evaluated 73 leadership development studies, including 5654 participants in total with $78 \%$ of the samples at the undergraduate level and $16 \%$ of samples at the graduate level. Reyes et al. utilized Kirkpatrick's training evaluation framework when evaluating the effectiveness of leadership development programs. Kirkpatrick identified four primary types of outcomes which included: trainee reactions (opinions, perceived utility); learning (level of knowledge related to targeted KSA); transfer of training (extent of application of KSA to the workplace); and results (organizational outcomes, e.g. financial, turnover, etc.) (Kirkpatrick, 1959). Reyes et al. report that $43.1 \%$ of studies measured skill-based outcomes; $20.8 \%$ measured affective outcomes, $6.9 \%$ measured cognitive outcomes only, and $29.2 \%$ measured a combination of outcomes. Reyes et al. also indicated that the following methods were used by these leadership development programs to evaluate program outcomes: self-report methods $(80.8 \%)$; peer-ratings $(1.4 \%)$; observers $(5.5 \%)$, objective reports $(4.1 \%)$, and $8.2 \%$ used multiple methods (either self-report and observer ratings, self-report and objective ratings, selfreport and peer ratings, or self-report, objective, and observer ratings) (Reyes et al., 2019).

Reyes et al. report that leadership development programs in higher education are increasing 'learning' by $19 \%$ but the 'transfer of learning' lags behind, with an increase of $14 \%$. The authors recognize that the lack of transfer of learning to the workplace is well documented in the training literature but also suggest that it may be a result of a lack of transfer focus within the leadership development programs, or may be related to constraints on gathering transfer data within the educational environment, as compared to an organization providing training to their 
employees. Due to a small size, they were unable to test the effect of the leadership development programs on 'reactions' and 'result' outcomes.

Their review indicated that most programs focus on skill-based learning (including communicating, persuading others, setting goals, and problem solving), and suggest that future research also evaluate cognitive and affective outcomes, as these have been shown to be important in shaping behaviors (Kahle \& Berman, 1979). Their review also indicated that most programs used approaches to program implementation that were convenient and inexpensive and suggest that programs should include more practice, such as reflective activities, role-play, goal setting, and games. Given that the majority of programs used self-report assessments, Reyes et al. also suggest that researchers consider best practices for program evaluation, in particular, to avoid endogeneity concerns within the evaluation data. Through their meta-analysis, they identified three dominant concerns that threaten causal inference within the examined studies: 1) non-random assignment to treatment and control groups; 2) self-selection bias (when programs are voluntary); and 3) the use of a single method for self-reporting. The majority (63.2\%) of the programs studied in the meta-analysis had all three issues, and the remaining programs had either two of the issues $(24.6 \%)$ or one of the issues $(12.3 \%)$.

Antonakis et al. (2010) discuss these common issues within social science research, specifically in the context of leadership research. Antonakis et al. indicate that endogeneity is a critical issue that is present in an alarming number of studies in the literature, and that impacts our ability to make causal inferences. In order for causal relationships to be inferred, the independent variable must vary randomly, and must not be correlated with other causes not examined (exogeneity). Self-selection into leadership development programs results in a non-random treatment group. There may be other variables that impact self-selection (such as IQ, extroversion, emotional intelligence, etc.) that may be related to self-selection and leadership abilities. The authors highlight the gold standard in treatment evaluation as a randomly assigned and representative sample compared to an equivalent control group. However, they also acknowledge that this is not possible in many instances and provide an in-depth review of the problematic issues confronting many research studies in the leadership literature as well as recommendations on how to design research studies to address these common issues.

They recommend several methods for inferring causality in non-experimental settings:

"Propensity score analysis: Compare individuals who were selected to treatment to statistically similar controls using a matching algorithm; Simultaneous-equation models: Using "instruments" (exogenous sources of variance that do not correlate with the error term) to purge the endogenous x variable from bias.; Regression discontinuity: Select individuals to treatment using a modelled cut-off.; Difference-in-differences models: Compare a group who received an exogenous treatment to a similar control group over time; Heckman selection models: Predict selection to treatment (where treatment is endogenous) and then control for unmodeled selection to treatment in predicting y." (Antonakis et al., 2010).

The current study, described here, evaluates a leadership development program, within a university, but from the perspective of alumni currently working in the engineering field. An aim of this study is to address one of the weaknesses noted in the meta-analysis by Reyes et al. (2019), which was the need to evaluate the 'results' of the leadership development program. 
While a common approach in program evaluation is to evaluate the program in terms of how the program (or course) is meeting the learning objectives or outcomes of the program (or course). In the current study, the 'results' of the program are evaluated in terms of the potential impact the leadership development program had on alumni in getting their first job and on subsequent career progression. The impact of the program is assessed in terms of the participants' perceived impact, rather than an empirical evaluation. The data reported here are part of a work-inprogress, where the final goal of this study is to compare survey results from the leadership development alumni to matched controls that were college of engineering alumni who did not complete the leadership minor. The use of a control group is intended to partially control for endogenous bias described above. The intention of the larger study is to collect representative data to match leadership program alumni and college of engineering 'control' alumni on gender, age range, discipline, and undergraduate GPA, in an effort to evaluate job placement, starting salary, and career progression as a function of participation in the leadership program, independent of these demographic variables.

\section{Methods}

\section{Study Overview}

Alumni from an undergraduate Engineering Leadership Development Minor were surveyed to assess the impact that the program had on helping them get their first job, helping them get one or more promotions, and in helping them to develop the skills needed for today's engineering work. Alumni were sent a link to a survey and offered a \$10 gift certificate to Amazon and an ELD lapel pin for their participation.

\section{Participants}

Study participants were alumni of the Engineering Leadership Development Minor (ELDM) at Penn State University. At the time of this study (spring 2019), 798 alumni were identified from the ELDM program. However, given the program spans the last 25 years, current contact information was not readily available. Of the 798 alumni, when contact information was available, it was often limited to the student's PSU email, which becomes inactive roughly 6 months after a student graduates. Efforts to obtain current contact information were made utilizing social media, including LinkedIn and Facebook. Social media presented several obstacles, such as a lack of information (such as major/minor), when trying to identify individuals with common first and last names. There was a higher success rate when using LinkedIn, but neither rate was greater than $40 \%$. Current contact information was obtained for 451 alumni. Of the 451 alumni, 136 participated in this study, resulting in a $30.2 \%$ response rate. Of those that responded, $67 \%$ were male and $32 \%$ were female, consistent with recent gender composition within the ELDM, with $63 \%$ male and $37 \%$ female. Table 1 summarizes the number and percentage of study participants by age range. Table 2 summarizes the number and percentage of students by their undergraduate major. Electrical Engineering, Industrial and Manufacturing Engineering, and Mechanical Engineering were the top undergraduate majors represented by survey respondents. 
Table 1: Number and percentage of participants by age range.

\begin{tabular}{|c|c|c|}
\hline Age Range & N & \% of Respondents \\
\hline $24-26$ & 19 & $14 \%$ \\
\hline $27-29$ & 32 & $24 \%$ \\
\hline $30-32$ & 21 & $15 \%$ \\
\hline $33-35$ & 32 & $24 \%$ \\
\hline $36-38$ & 22 & $16 \%$ \\
\hline $39-40$ & 5 & $4 \%$ \\
\hline $41-43$ & 5 & $4 \%$ \\
\hline
\end{tabular}

Table 2: Number and percentage of participants by undergraduate major.

\begin{tabular}{|l|c|c|}
\hline Major & $\mathbf{N}$ & $\mathbf{\%}$ \\
\hline Aerospace Engineering & 9 & $7 \%$ \\
\hline Agricultural and Biological Engineering & 1 & $1 \%$ \\
\hline Architectural Engineering & 2 & $1 \%$ \\
\hline Biomedical Engineering & 3 & $2 \%$ \\
\hline Chemical Engineering & 12 & $9 \%$ \\
\hline Civil and Environmental Engineering & 12 & $9 \%$ \\
\hline Computer Science & 8 & $6 \%$ \\
\hline Electrical Engineering & 14 & $10 \%$ \\
\hline Engineering Science and Mechanics & 1 & $1 \%$ \\
\hline Industrial and Manufacturing Engineering & 23 & $17 \%$ \\
\hline Mechanical Engineering & 33 & $24 \%$ \\
\hline Nuclear Engineering & 2 & $1 \%$ \\
\hline Other & 16 & $12 \%$ \\
\hline
\end{tabular}

\section{Engineering Leadership Development Minor (ELDM) Program Description}

The Engineering Leadership Development Minor (ELDM) Program at Penn State University was created in 1995; 25 years and running (Schuhmann et al., 2015) The ELD Minor is an 18 credit undergraduate minor structured to allow customization based on student career goals and interests. The minor has had some modifications over the last 25 years. The current minor format requires two courses on Leadership Principles and Technology-Based Entrepreneurship (3-credits each). In addition, students must choose another 6 credits from the following four courses: Leadership in Organizations, International Leadership of Engineering and Development, Project Management for Professionals, or an independent study which could take the form of an international project, a coaching course, or an honors thesis). The final requirement includes an 
additional 6 credits which are selected from an approved elective list. The curriculum emphasizes the development of leadership potential within each student, a multicultural awareness, and opportunities to exercise their skills through hands-on, leadership challenges.

\section{Survey Instrument}

An alumni survey was developed to align with the learning outcomes of the ELD minor courses and to assess the impact of participation in the ELD minor on initial job placement, effectiveness on the job, and career progression. The results reported here focus on three Likert scale questions related to the impact of the minor on initial job placement, effectiveness on the job, and career progression. The survey instrument was deployed using Qualtrics Survey Software. A link to the survey was initially sent through Qualtrics using a panel and the automated system within Qualtrics. However, it was immediately brought to the attention of the program director that respondents were concerned that the email was a scam. The survey link was resent directly from the program director to alleviate those initial concerns. Approximately two and a half weeks after the initial distribution of the survey, a follow-up email was sent to alumni that had not yet responded.

The current study focuses on participant responses to three statements. Respondents were asked to indicate their level of agreement with the statements based on a Likert-scale: Strongly Disagree, Disagree, Neutral, Agree, Strongly Agree. The three statements were:

1. The ELD program was instrumental in helping me get my first job.

2. The ELD program was instrumental in helping me get one or more promotions.

3. The ELD program helped me develop skills needed for today's engineering work.

These survey questions were intended to assess whether the alumni regarded their participation in the leadership development program as important in their initial hire and subsequent career progression. In addition, the third survey item was used to assess whether alumni believed that the program's developmental objectives were meeting the needs of our graduates in the workplace.

\section{Results}

Based on participants perceived influence, the results from the alumni survey (Figure 1) indicated that the ELD program was instrumental in helping ELD minor graduates in getting their first job (64\% responded strongly agree or agree) and in getting one or more promotions (57\% responded strongly agree or agree). In addition, the survey results indicate that the program helped to develop the skills needed for today's engineering work ( $86 \%$ responded strongly agree or agree). 
Figure 1: Number of participants that responded to each element of the Likert scale Strongly Disagree, Disagree, Neutral, Agree, Strongly Agree) for each survey statement.

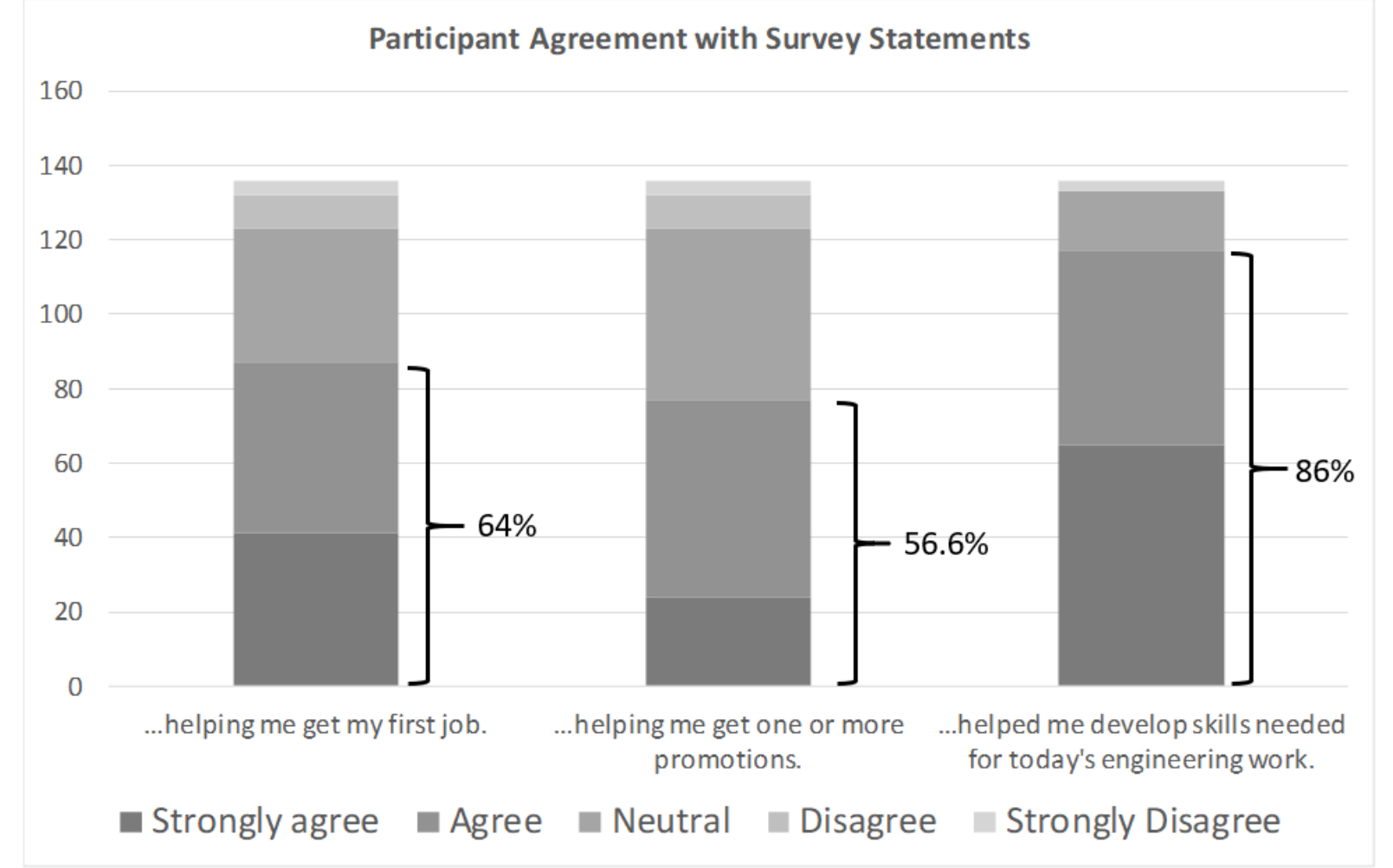

\section{Discussion and Conclusions}

To date, the program has previously reported outcomes from assessments of 'learning' and 'transfer of learning' that occurred in our gateway to minor entry course, on Leadership Principles (Handley et al., 2017; Handley et al., 2019; Hochstedt et al., 2013; Lang et al., 2018; and Park et al., 2019) as well as our International Leadership of Engineering and Development course (Gordon, et al., 2014).

The results presented here reflect the program's initial attempt to assess the impact of the leadership development program on outcomes beyond the 'learning' and 'transfer of learning' outcomes that are most often reported in the literature. Based on self-report data, the majority of alumni of the Engineering Leadership Development minor report that participation in the minor helped them get their first job, and to a slightly lessor extent, one or more subsequent promotions. Alumni overwhelmingly reported that the ELD minor helped them develop skills needed for today's engineering work. These preliminary results are encouraging but do not tell the whole story. As described above, self-selection into the leadership development program can bias results.

Additionally, we have not yet examined the survey results with regard to the number of years since graduation or the positions held within an organization. The overall age range spanned from 24 to 43 years of age, with a corresponding large range of years since graduation from the program. It is also possible that respondents with experience in leadership positions within an 
organization will rate the impact of the program differently than respondents that have not held leadership positions.

\section{Study Limitations and Future Directions}

As mentioned previously, a limitation of this, and many leadership development program assessments, is the self-selection bias that is unavoidable with 'voluntary' participation, such as is the case with the decision to complete an undergraduate Engineering Leadership Development minor. Another limitation of this study is that this is the first survey of alumni that graduated over a period of 20 years. Recalling how the program impacted the first job or initial promotions may be more difficult for alumni that graduated 5-15 years ago compared to more recent graduates. Long term goals of the program are to conduct pre and post learning outcome assessments of program participants as they enter the minor and upon graduation as well as periodic (every 3-5 years) longitudinal assessments of alumni to track the perceived impact of the program on career progression on an ongoing basis. It is anticipated that the learning outcomes assessments will be used in combination with the longitudinal alumni assessments.

Future work will also explore whether participation in the leadership development program results in differences in salary level, job placement, career progression, and leadership responsibilities as compared similar graduates not in the leadership program. In addition, follow up work will aim at better understanding where improvements can be made within the leadership development curriculum.

\section{References}

ABET (2020) Criteria for Accrediting Engineering Programs. Retrieved from: https://www.abet.org/accreditation/accreditation-criteria/criteria-for-accreditingengineering-programs-2020-2021/.

Antonakis, J., Bendahan, S., Jacquart, P., \& Lalive, R. (2010). On making causal claims: A review and recommendations. The Leadership Quarterly, 21, 1086-1120.

Avolio, B. J., Reichard, R. J., Hannah, S. T., Walumbwa, F. O., \& Chan, A. (2009). A metanalytic review of leadership impact research: Experimental and quasi-experimental studies. The Leadership Quarterly, 20, 764-784.

Burke, M. J., \& Day, R. R. (1986). A cumulative study of the effectiveness of managerial training. Journal of Applied Psychology, 71, 232-265.

Collins, D. B., \& Holton, E. F. (2004). The effectiveness of managerial leadership development programs: A meta-analysis of studies from 1982 to 2001 . Human Resource Development Quarterly, 15, 217-248.

Gordon, A., Devon, R.F., Erdman, A.M., Atieh, A. Doetrich, P. (2014) Cultural Accommodation in Virtual Engineering Academic Teams. American Society for Engineering Education Annual Conference and Exposition. Indianapolis, IN, June 2014.

Handley, M.H., Lang, D.H., \& Erdman, A.M. (2017). First Impressions: Evaluating Student Performance in Demonstrating Engineering Leadership. American Society for Engineering Education Annual Conference and Exposition. Columbus, OH, June 2017. 
Handley, M., Lang, D.H., Erdman, A. M., Park, J.J. (2019) Leaders as Coaches. Conference Paper and Presentation: American Society for Engineering Education Annual Conference and Exposition, Tampa, FL, June 2019.

Hochstedt, K.S., Erdman, A.M., and Schuhmann, R.J. (2013) Learning Expectations and Outcomes for an Engineering Leadership Principles Class. American Society for Engineering Education Annual Conference and Exposition. Atlanta, GA, June 2013.

Kahle, L. R., \& Berman, J. J. (1979). Attitudes cause behaviors: A cross-lagged panel analysis. Journal of Personality and Social Psychology, 37(3), 315-321.

Kirkpatrick, D. (1959). Techniques for evaluating training programs. Journal of the American Society for Training and Development, 13, 3-9.

Lacerenza, C. N., Reyes, D. L., Marlow, S. L., Joseph, D. L., \& Salas, E. (2017). Leadership training design, delivery, and implementation: A meta-analysis. Journal of Applied Psychology, 102(12), 1686-1718.

Lang, D.H., Handley, M., \& Erdman, A. M. (2018) Flipped classroom and emotional learning in an engineering leadership development course. American Society for Engineering Education Annual Conference and Exposition, Salt Lake City, UT April, 2018.

Park, J., Lang, D.H., Handley, M.H., \& Erdman, A.M. (2019) Developing undergraduates' selfefficacy for engineering leadership: relations among leadership attributes, teamwork skills, and creativity. Conference Paper and Presentation: American Educational Research Association Annual Conference, Toronto, Canada, 2019.

Powell, K. S., \& Yalcin, S. (2010). Managerial training effectiveness: A meta-analysis 19522002. Personnel Review, 39, 227-241.

Reyes, D.L., Dinh, J, Lacerenza, C.N., Marlow, S.L., Joseph, D.L., and Salas, E. (2019) The state of higher education leadership development program evaluation: A meta-analysis, critical review, and recommendations. The Leadership Quarterly Vol. 30(5) https://doi.org/10.1016/i.leaqua.2019.101311

Schuhmann, R. J., \& Erdman, A. M., \& Matson, J. V., \& Lang, D. H., \& Soper, J. G., \& Horner, D. H. (2015), Engineering Leadership Education - The Path Forward. American Society for Engineering Education Annual Conference and Exposition, Seattle, Washington, June, 2015. 10.18260/p.23971. 